\title{
Apendiks mukoseli radyolojik tanısı
}

\author{
Radiological diagnosis of appendiceal mucocele \\ Kayhan Karakuş*, Hacı Ahmet Sümbül, Ahmet Müslehiddinoğlu, İsmail Şalk
}

Radyoloji Kliniği (Dr. K. Karakuş), Genel Cerrahi Kliniği (Dr. H.A. Sümbül), Patoloji Kliniği (Dr. A. Müslehiddinoğlu), Tokat Devlet Hastanesi, TR-60100 Tokat, Radyoloji Kliniği (Yrd. Doç. Dr. İ. Şalk), Cumhuriyet Üniversitesi Tıp Fakültesi TR-58140 Sivas

\section{Özet}

Apendiks mukoseli müsin birikimine bağlı apendiks lümeninin kronik kistik dilatasyonudur. Nadir izlenir ve nadiren operasyon öncesi teşhis edilir. Cerrahi sırasında ya da spontan rüptüre olması durumunda psödomiksoma peritonei gelişebilir. Operasyon öncesi apendiks mukoseli tanısı konulması yararlıdır. Bu çalışmada operasyon öncesi radyolojik olarak tanısı konmuş apendiks mukoseli sunulmuştur.

Anahtar sözcükler: Mukosel, psödomiksoma peritonei, ultrasonografi, bilgisayarlı tomografi

\begin{abstract}
Appendix mucoceles is a chronic cystic dilatation of appendix lumen that occurs due to accumulation of mucin. It is a rare entity and is rarely diagnosed prior to operation. Pseudomyxoma peritonei can occurr due to surgical application or spontaneous rupture. Diagnosis of appendix mucoceles is useful. In this study, the preoperative radiological diagnosis of appendiceal mucocele is presented.
\end{abstract}

Keywords: Mucocele, pseudomyxoma peritonei, ultrasound, computed tomography

Geliş tarihi/Received: 13 Şubat 2012; Kabul tarihi/Accepted: 03 Eylül 2012

*İletişim adresi:

Dr. Kayhan Karakuş, Radyoloji Kliniği, Tokat Devlet Hastanesi, TR-60100 Tokat. E-posta: drkayhan58@gmail.com

\section{Giriş}

Apendiks mukoseli nadir görülür. Sıklıkla apendiks mukozasının neoplastik değişikliklerine bağglı gelişir [1]. Kistadenom ve kistadenokarsinom gibi müsin salan epitelyal tümörlere bağlı olarak apendiks lümeninde yoğun müsin birikimi kistik dilatasyona neden olur [2]. Komplikasyonlarının ciddi olmasından dolayı apendiks mukoselinde erken tanı konulması önemlidir [1, 2]. Apendiks mukoseli tanısında radyolojik yöntemler kullanılır $[1,2]$. Bu yazıda, müsinoz kistadenoma bağlı bir apendiks mukoseli olgusu sunulmaktadır.

\section{Olgu sunumu}

Batın sağ alt kadranda ağrı şikayeti ile başvuran 58 yaşındaki kadın hastanın daha önceden abdominal cerrahi geçirmediği öğrenildi. Fizik muayenesinde, batın sağ alt kadranda hassasiyet belirlendi. Rutin laboratuar inceleme sonuçları normaldi. Ultrasonografi (US) incelemede çekumun inferiorunda, yaklaş1k 7x3,5 cm boyutlarında, yer yer internal ekolar içeren, ince duvarlı fuziform şekilli kistik kitle izlendi (Resim 1). Pelvik bölgeye yönelik yapılan kontrastsız bilgisayarlı tomografi (BT)incelemede çekal bölgede ince ve düzgün duvarlı, lokal ince lineer kalsifikasyon içeren, sıvı dansitesine (20 HU) sahip bir kitle saptand1 (Resim 2). 

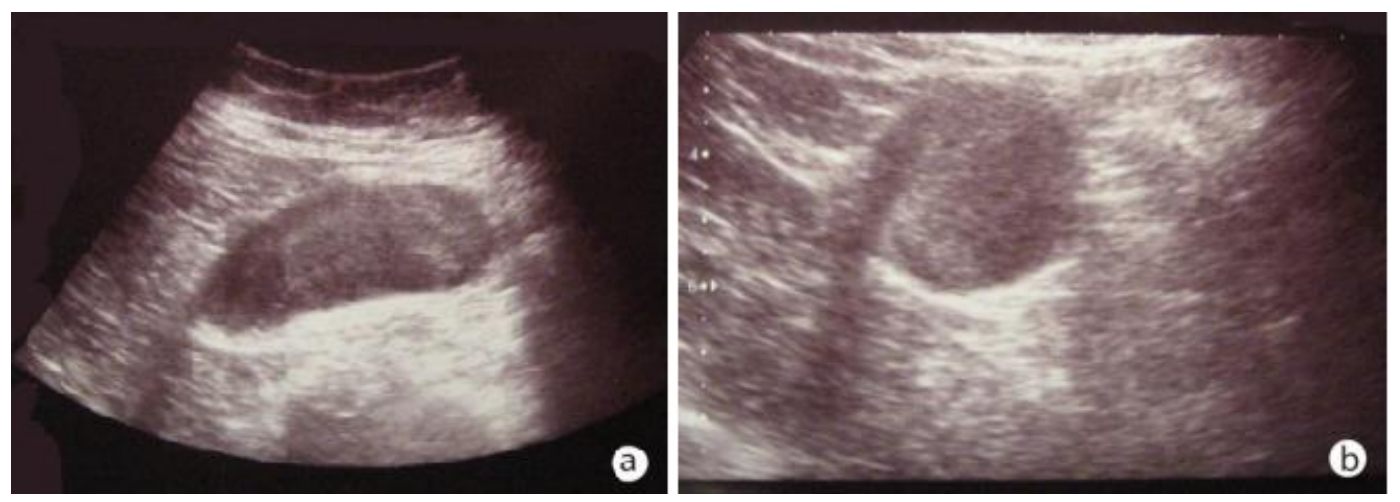

Resim 1. 58 yaşında kadın hastada sağ ilyak fossa yerleşimli kistik kitle. Transabdominal US' de iyi sınırlı tubüler yapıda ince duvarlı ve posterior akustik güçlenme gösteren yer yer internal ekojeniteler içeren kistik lezyon a. Longitudinal b. Transvers US görünümü.
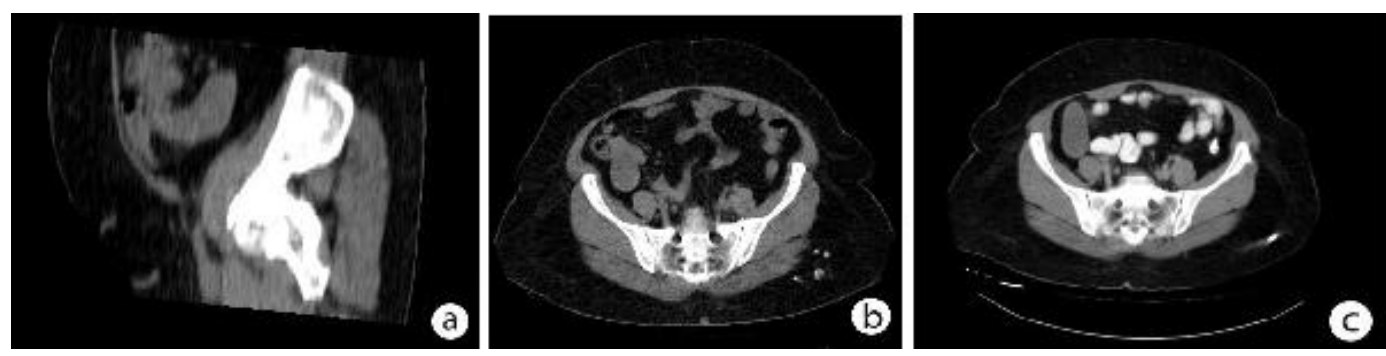

Resim 2. Sagittal BT reformat görüntüde sağ iliyak fossada çekum ile ilişkili kistik lezyon izlendi (a). Kist duvarında lokal ince lineer kalsifikasyon mevcuttu (b). Kistin ince düzgün duvarlı olduğu ve kontrastlı BT incelemede (c) kist duvarında kontrastlanan nodüler oluşumların olmadığı izlenmektedir.

Oral ve intravenöz kontrast madde kullanılarak pelvik bölgede yönelik yapılan BT incelemede periçekal yerleşimli kistik lezyonun duvarında kontrast tutulumu olmadığ izlendi. Yapılan abdominal Manyetik rezonans (MR) görüntülemede periçekal yerleşimli lezyonun T1 ağırlıklı görüntülerde hipointens, T2 ağırlıklı görüntülerde hiperintens olduğu, intravenöz gadolinium sonrası elde edilen postkontrast serilerde ise lezyon duvarında hafif kontrastlanma olduğu izlendi (Resim 3).
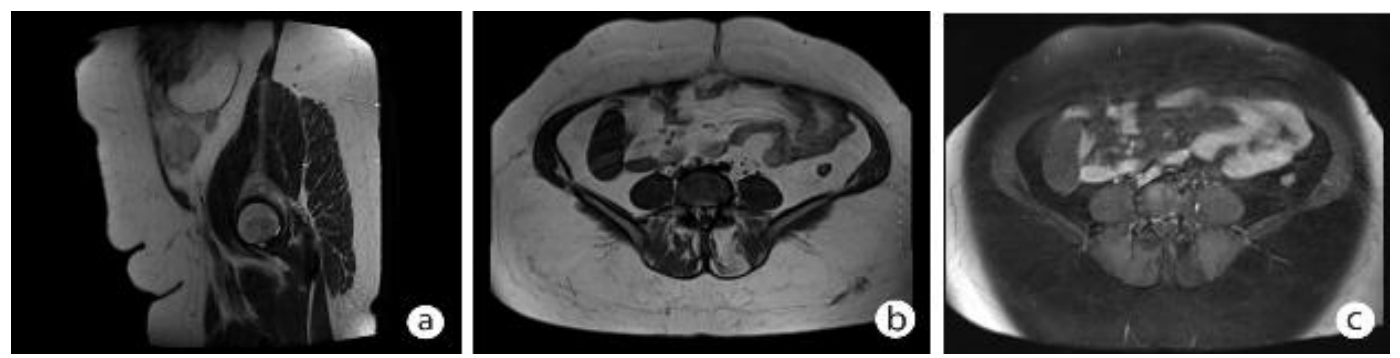

Resim 3. T2 ağırlıklı sagital (a), T1 ağırlıklı aksiyel (b) ve T1 ağırlıklı yağ baskılı kontrastlı aksiyel (c) imajlarda çekum ile ilişkili $7 \times 3,5 \mathrm{~cm}$ boyutlarında dilate kistik lezyona ait görünüm izlenmektedir. Postkontrast serilerde lezyon duvarında kontrast tutulumu olduğu izlenmektedir.

Ayrıca T2 ağırlıklı koronal imajlarda yağ baskılı (a) ve su baskılı (b) ardışık görüntülerde sirasıyla hiperintens ve hipointens olarak izlenen lezyonun kistik karakterde olduğu saptand1 (Resim 4). 

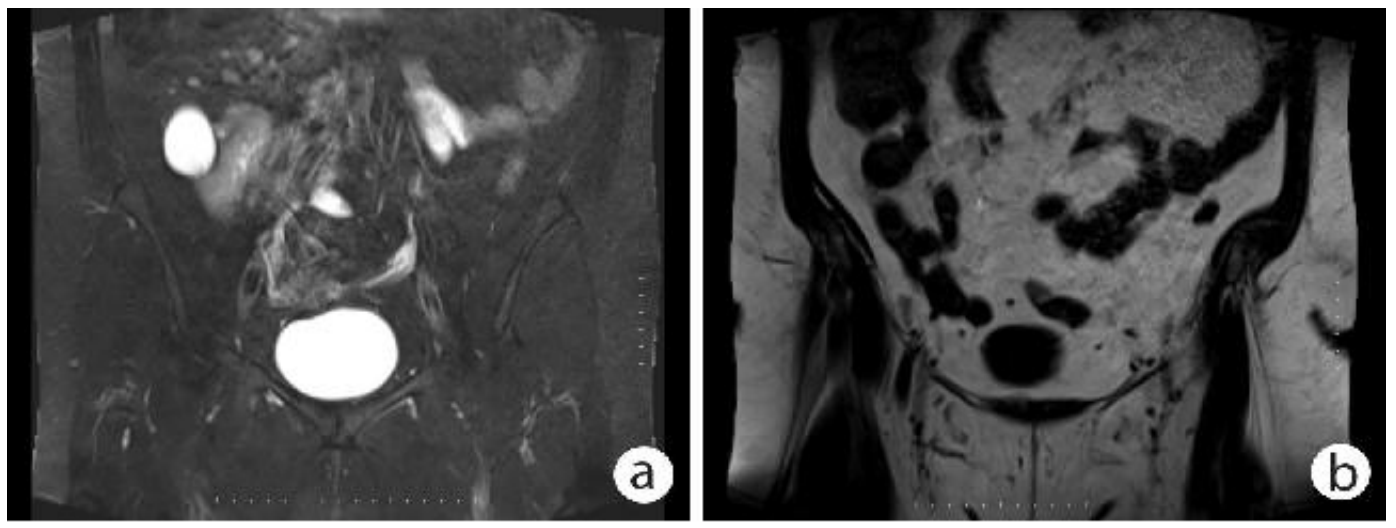

Resim 4. T2 ağırlıkıı koronal dixon imajlarda yă̆ baskılı (a) ve su baskılı (b) ardışık görüntülerde lezyonun kistik özelliği dikkati çekmektedir.

$\mathrm{Bu}$ bulgulara göre lezyon apendiks mukoseli olarak tanımlandı. Kolonoskopik incelemede eşlik eden başka lezyon saptanmadı. Ameliyat sırasında mukosel, dikkatli bir şekilde rezeke edildi (Resim 5).
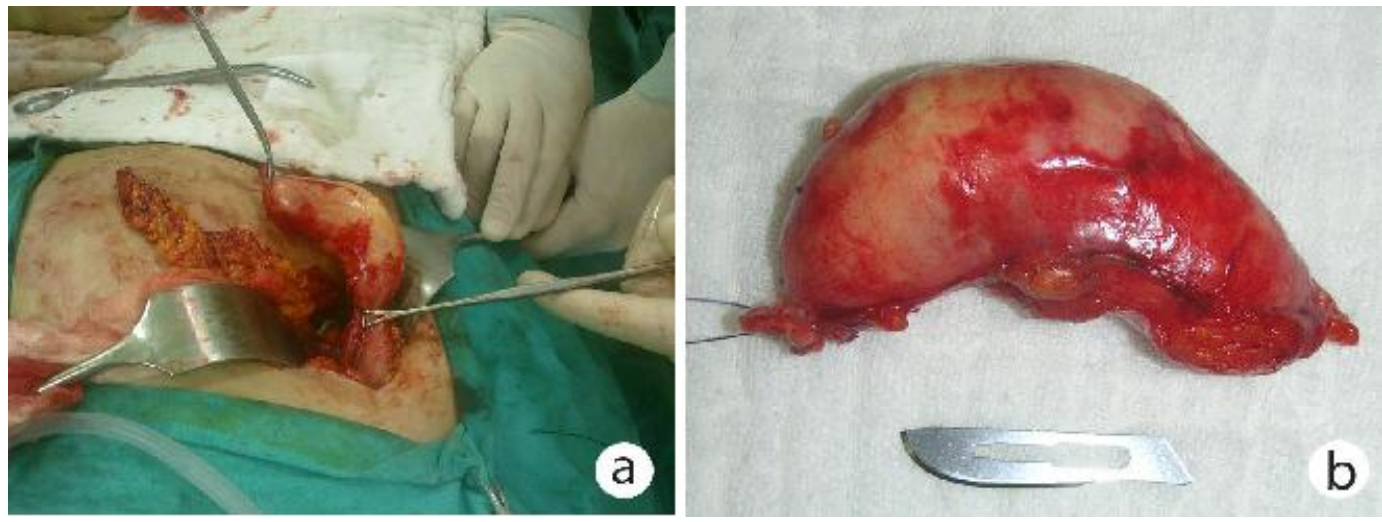

Resim 5. Cerrahi esnasında (a) ve rezeke edilmiş spesmenin (b) fotoğraflarında kistik lezyonun çekum ile olan ilişkisi ve dilate apendikse ait görünüm izlenmektedir.

Patolojik incelemede, apendiks mukoseline sebep olan lezyonun kistadenom olduğu tespit edildi (Resim 6).

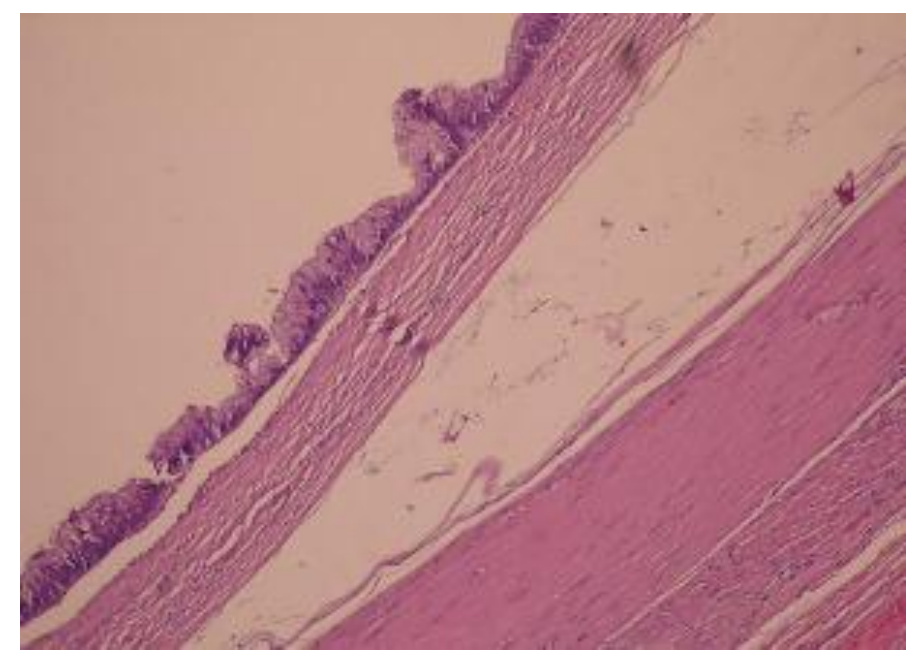

Resim 6. Patolojik incelemede lezyonun yer yer papiller konfigürasyonda epitel ile döşeli olup duvarında fibrozis ve fokal kronik iltihap içerdiği izlenmektedir (H\&E 50). 


\section{Tartışma}

Müsin birikimine bağlı apendiks lümeninin kronik kistik dilatasyonuna mukosel denir [1, 2]. Yuvarlak veya oval şekilli, ince duvarlı ve periçekal lokalizasyondaki, 3-6 cm çapta kistik kitle mukosel için tanısaldır [1,2]. Apendiks mukoseli nadirdir ve apendektomi yapılan hastalarda sıklı̆̆ \%0,2-0,3 olarak bildirilmiştir [2]. Hastalar genellikle 50 yaşın üzerindedir ve kadınlarda erkeklere göre dört kat daha sık izlenmektedir [1,2]. Genellikle asemptomatik olmakla birlikte en sık semptom akut veya kronik sağ alt kadran ağrısıdır [2]. Sağ alt kadranda uzun süreli belirsiz bir rahatsızlık hissi ve nadiren mukoselin çekum içine invajinasyonuna bağlı intermittan ağrı görülebilir, kitle palpe edilebilir $[1,2]$. Olgumuzun son 3 aydır mevcut olan batın sağ alt kadranda ağrı şikayeti vardı ve fizik muayenesinde batın sağ alt kadranda hassasiyet belirlendi.

İnflamatuar skar dokusu, apendiks karsinomu, endometrioma, fekalit, çekum ve kolonun tümör, karsinoid, polip ve volvulus gibi lezyonları ile apendiks lümeni obstrükte olabileceği gibi histopatolojik çalışmalar apendiks mukozasında gelişen neoplastik değişikliklerin de mukosele yol açtığını göstermiştir. Dört histolojik subtipi vardır; retansiyon kisti, mukozal hiperplazi, kistadenom ve kistadenokarsinom [2, 3]. Kistadenom ve kistadenokarsinom müsin sekrete eden tümörlerdir. Benign kistadenoma benign mukosel de denir ve en sik izlenen tiptir. Kistadenokarsinom sıklığı kistadenomun 1/5'i olmasına rağmen bu tipte perforasyon riski ve psödomiksoma peritonei gelişme riski kistadenoma göre oldukça yüksektir. Ayrıca kistadenokarsinoma bağlı gelişen psödomiksoma peritoneide 5 yıllık sağkalım oranı \%20'lere kadar düşmektedir [3, 4]. Bizim olgumuzda histopatolojik incelemede, apendiks mukoseline sebep olan lezyonun kistadenom olduğu tespit edildi. Operasyon öncesi mukoselin tanınması cerrahi sırasında rüptürden kaçınmak açısından önemlidir, rüptüre edilirse psödomiksoma peritonei gelişir [4]. Rüptür, torsiyon ve barsak obstrüksiyonu apendiks mukoseline bağlı gelişen komplikasyonlardır. Malign transformasyon olasılığının saptanması da cerrahi yöntem seçimi açısından önemlidir [3]. Apendiks mukoselinin tipik radyolojik bulgusu, apendiks bölgesinde kistik kitle varlığıdır. Düz karın grafisinde sağ alt kadranda, kalsifikasyonu içerebilen yumuşak doku kitlesi şeklinde görülebilir. Baryumlu kolon grafisinde çekuma, terminal ileuma veya sigmoid kolona dişarıdan bası izlenebilir ve apendiks lümeninin dolmadığı görülür $[1,3]$. Ultrasonografide büyük, hipoekoik, iyi sınırlı sağ alt kadran yerleşimli kistik kitle görünümü tipiktir. Kitlenin internal ekojenitesi, duvar kalınlığı ve duvar kalsifikasyonu değişkenlik gösterebilir. Bazen duvarında mukozal proliferasyona bağlı papiller çıkıntılar bulunabilir. İnternal içerik sekrete edilen mukusun özelliğine bağlı olarak laminer ya da girdapvari görünüm sergileyebilir. Mukosel sıklıkla retroçekal yerleşimli ve mobil olarak izlenir. BT'de pelvik bölgede sıvı dansitesinde iyi sınırlı kistik kitle izlenir. Kist duvarında ya da lümen içinde kurvilineer kalsifikasyon izlenebilir. Müsinöz kistadenom ise enkapsüle hipodens kistik kitle olup retansiyon mukoselinden ayırtedilemez. Müsinöz kistadenokarsinom kalınlaşmış nodüler duvar yapısı olan büyük düzensiz sınırlı kitledir, solid ve kistik alanlar içerebilir, solid kompanentinde kalsifikasyon izlenebilir. Kist duvarının değişken kalınlıkta olmasından ziyade kist duvarında kontrastlanan mural nodül saptanması malign transformasyonu göstermesi açısından daha anlamlıdır. Kontrastlı serilerde dilate apendiks duvarında fokal kontrastlanan nodül saptanması özellikle altta yatan kistadenokarsinom açısından anlamlıdır. Mukoselin sıvı içeriği baskınsa T1 ağırlıklı görüntülerde hipointens, T2 ağırlıklı görüntülerde hiperintens, mukoselin müsin içeriği baskınsa MR'da T1 ağırlıklı ve T2 ağırlıklı görüntülerde hiperintens sinyal intensitesinde izlenir [5-7]. Olgumuzda lezyonun radyolojik bulguları literatür bilgileri ile uyumludur.

Apendiks mukoselinin ayırıcı tanısında akut apandisit, apendiks karsinomu, apendiks lenfoması, çekum karsinomu ve over kaynaklı kistleri düşünülmelidir. Akut apandisitte inflamatuar değişiklikler ön planda olup abse gelişmesi durumunda lezyon duvarında düzensiz kalınlaşma izlenebilir. Apendiks karsinomunda düzensiz sınırlı mikst dansitede kitle izlenir. Apendiks lenfomasında periçekal yerleşimli solid kitle izlenir. Çekal 
karsinom obstrüksiyona bağlı apendiks dilatasyonuna neden olabilir. Pelvis yerleşimli apendiks gibi apendiksin anormal pozisyonda olduğu durumlarda mukosel kompleks adneksiyal kitleler ile de karışabilir. CA 19-9 ve CA 125 gibi tümör markerleri kist sıvısında yüksek bulunmuştur. Ayrıca apendiks mukoselinde kolonik adenokarsinom gelişme riski altı kat artmıştır [1, 7-9]. Olgumuzda kolonoskopik incelemede eşlik eden başka lezyon saptanmad. Benign kistadenom tedavisinde apendektomi yeterli iken kistadenokarsinom eğer rezektabıl ise sağ hemikolektomi uygulanır $[10,11]$.

Sonuç olarak, sağ alt kadran ağrısı olan ya da radyolojik olarak sağ alt kadranda kistik kitle saptanan hastalarda ayırıcı tanıda apendiks mukoseli de düşünülmelidir. Apendiks mukoseli apandisit şüphesi ile laparotomi yapılan olgularda tesadüfen saptanır. Preoperatif olarak tanıda US, BT, MR faydalıdır.

\section{Kaynaklar}

1. Yazıcı Z, Savcı G, Yalçın R, Yılmazlar T. Apendiks mukoseli. Tanısal ve Girişimsel Radyoloji 2001; 7: 564-7.

2. Aho AJ, Heinonen R, Lauren P. Benign and malignant mucocele of the appendix. Acta Chir Scand 1973; 139: 392-400.

3. Pickhardt PJ, Levy AD, Rohrmann CA Jr, Kende AI. Primary neoplasms of the appendix: radiologic spectrum of disease with pathologic correlation. Radiographics 2003; 23: 645-62.

4. Dachman AH, Lichtenstein JE, Friedman AC. Mucocele of the appendix and pseudomyxoma peritonei. Am J Roentgenol 1985; 144: 923-9.

5. Rumack CM, Wilson SR, Charboneau JW. Diagnostic Ultrasound. Third ed. St.Louis, Missouri: Elsevier-Mosby, 2005: 309-10.

6. Kim SH, Lim HK, Lee WJ, Lim JH, Byun JY. Mucocele of the appendix: ultrasonographic and CT findings. Abdom Imaging 1998; 23: 292-6.

7. Federle MP, Jeffrey RB, Desser TS, Anne VS, Eraso A. Diagnostic Imaging. Abdomen. First ed. Salt Lake City, Utah: Amirsys, 2005; 1-5: 26-7.

8. Rudloff U, Malhotra S. Volvulus of an appendiceal mucocele: Report of a case. Surg Today 2007; 37: 514-7.

9. Scaffa C, Di Bella O, Tartaglia E, Rotondi M, Lup F, Messalli EM. Surgical approach to appendiceal mucocele mimicking an adnexal complex mass: case report. Eur J Gynaecol Oncol 2007; 28: 503-5.

10. Papaziogas B, Koutelidakis I, Tsiaousis P. Appendiceal mucocele: a retrospective analysis of 19 cases. J Gastrointest Cancer 2007; 38: 141-7.

11. Ruiz-Tovar J, Teruel DG, Castineiras VM, Dehesa AS, Quindos PL, Molina EM. Mucocele of the appendix. World J Surg 2007; 31: 542-8. 